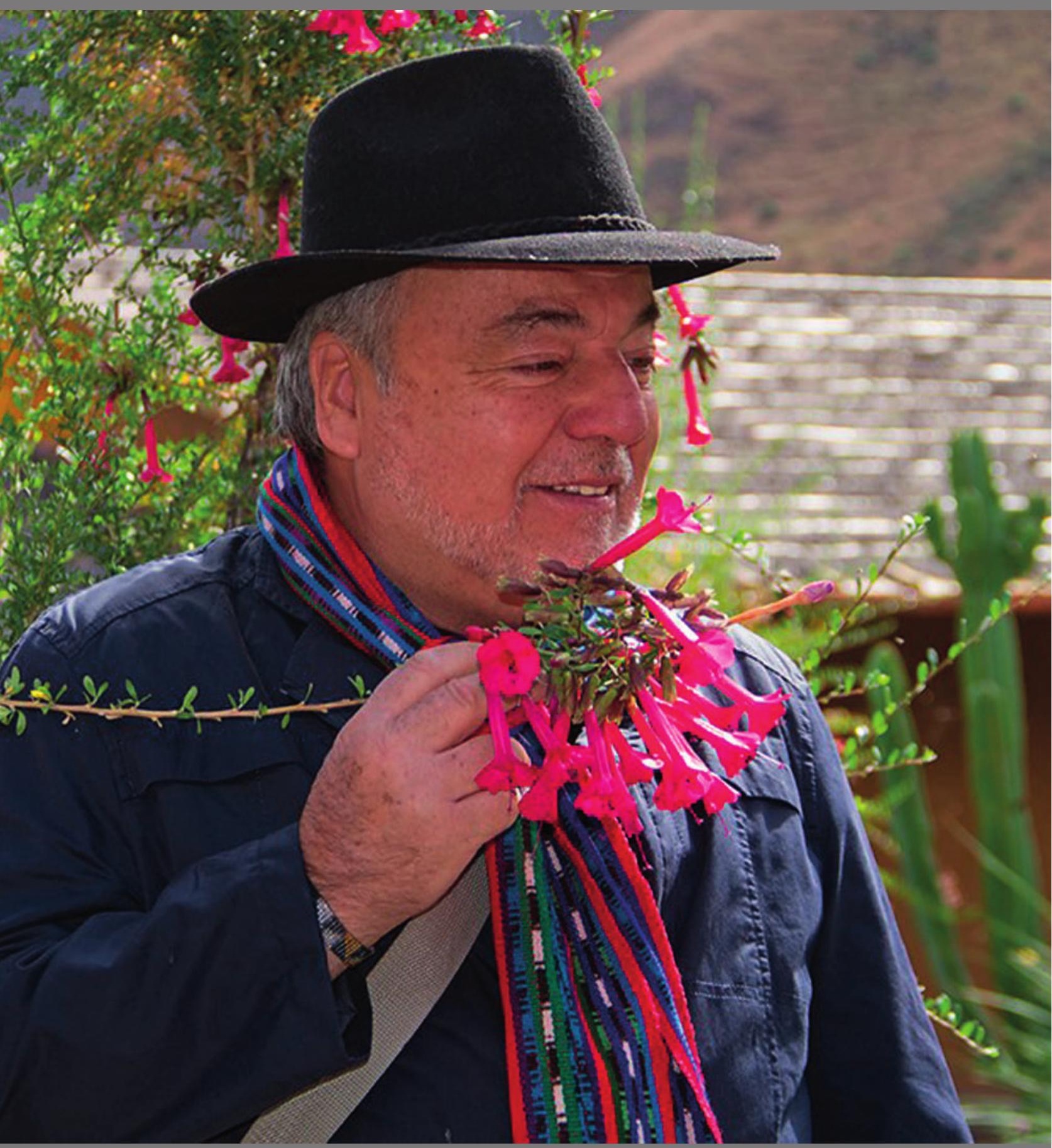

Luis Repetto Málaga. Foto: cortesía Edi Merida. 


\section{Luis Repetto Málaga}

(Lima, 1953 - Lima, 2020)

Claudio Mendoza Castro

Museo de Artes y Tradiciones Populares cmmendoza@pucp.edu.pe Lima-Perú

Tuve el privilegio de conocer y trabajar con Luis Repetto Málaga, Lucho, como le gustaba que le dijeran, y aprender de primera mano lo que significa el compromiso y la acción por la conservación, protección y difusión del patrimonio cultural de nuestro país, especialmente a través de su labor en el Museo de Artes y Tradiciones Populares del IRA-PUCP (el cual fundó), así como por su dedicación a la protección del patrimonio monumental arqueológico e histórico peruano, la conservación de los cementerios patrimoniales y su constante preocupación por el desarrollo de la museología en el Perú.

Lucho, al igual que muchos amantes del Perú y sus tradiciones, comenzó su acercamiento a nuestra cultura material e inmaterial desde muy joven. Él contaba que con sus primeros ahorros compraba "esas piezas andinas" que llegaban a las ferias artesanales de la avenida La Marina en su Pueblo Libre natal durante los años sesenta.

Sus primeros estudios fueron en Administración de Empresas, pero la admiración por descubrir las manifestaciones culturales de nuestro país jamás se le quitaron, pues aprendió diversos bailes peruanos, desarrollando una gran pasión por la marinera. Nunca perdía la oportunidad de sorprendernos con sus ágiles pasos al danzar nuestro baile nacional.

En la década de 1970, cuando trabajaba en Electro Lima, su interés por conocer más sobre nuestra cultura tradicional lo llevó a buscar un lugar donde aprender folclore. Así, llegó al Instituto Riva-Aguiero, donde conoció a la doctora Mildred Merino de Zela, destacada etnógrafa y folclorista peruana, quien dirigía el entonces Seminario de Folclore en el Instituto. Ella lo tomó como su discípulo y le presentó a importantes investigadores del folclore nacional e internacional. Las enseñanzas de la doctora Merino incentivaron su interés inicial y realizó viajes al interior del país, con la finalidad de conocer las manifestaciones más puras de lo que aprendía en la teoría.

Por esos años conoció a otra de sus musas, Rosa Alarco Larrabure, folclorista y musicóloga conectada con el mundo cultural peruano e internacional, quien le hizo descubrir que en su interior existía otro interés que luego sería su pasión: el mundo de los museos.

Los debates posteriores a la entrega del Premio Nacional de Cultura al destacado retablista ayacuchano Joaquín López Antay en 1975, fueron el germen de la idea y la necesidad de tener un espacio donde se recolecte, conserve y difunda el arte tradicional de nuestro país. Lucho compartió esta propuesta con Mildred Merino y Rosa Alarco, quienes lo apoyaron rotundamente. 
Así, el 25 de octubre de 1979 se inaugura el Museo de Arte Popular del Instituto RivaAgüiero (IRA) de la Pontificia Universidad Católica del Perú (PUCP). Con perseverancia, amor y pasión, Lucho fue recibiendo y buscando colecciones que desinteresados personajes e investigadores, como Mariano Benites, Elvira Luza y la misma Mildred Merino, fueron donando al joven museo. De esta forma comenzó a formarse el acervo de nuestra institución museística. Posteriormente en 1983, la necesidad de seguir aprendiendo acerca del mundo de los museos, hizo que Lucho estudiara una maestría en Museología en la Escuela Nacional de Conservación, Restauración y Museografía "Manuel del Castillo Negrete”, de México.

Con el pasar de los años, muchas más personas, empresas e instituciones apoyaron el esfuerzo de Lucho Repetto y el Museo de Arte Popular para la conservación del patrimonio cultural del país, entre ellas Gertrude Solari, Elvira Luza, los herederos de Arturo Jiménez Borja, los herederos de Guillermo Ugarte Chamorro, José Respaldiza, Doris Gibson, la empresa San Miguel Industrial, el Banco de Crédito del Perú, PlusPetrol, PromPerú, fueron algunos de los que confiaron en el imparable espíritu de Lucho.

En 1993, a iniciativa de Juan Ossio, el museo cambió su nombre a Museo de Artes y Tradiciones Populares del Instituto Riva-Aguiero de la Pontificia Universidad Católica del Perú (MATP-IRA-PUCP). Con esta nueva denominación, Lucho quiso mostrar que el acervo de nuestra institución iba más allá de las manifestaciones culturales físicas, pues integraba el concepto de tradición, que a su vez incluía las manifestaciones culturales inmateriales de nuestro país.

A la par de su trabajo en el Instituto, en la década de 1990 formó parte de la generación de gestores e impulsores que formaron el Centro Cultural de la Pontificia Universidad Católica del Perú, fue director de exposiciones y galerías de dicha institución y fue responsable de la gestión y montaje de muchas exhibiciones nacionales e internacionales durante casi diez años. A finales de la década de los noventa del siglo pasado, fue designado como director nacional del Instituto Nacional de Cultura.

También fue director del Museo de la Electricidad, importante espacio para la difusión de las ciencias en nuestro país, ubicado en el distrito de Barranco, cuya creación, en 1994, fue gestionada por Lucho con el apoyo de Electro Perú. En este espacio museístico, los visitantes podían acceder al conocimiento de temas científicos a través de una exposición interactiva. Lucho dividía su tiempo entre el Museo de la Electricidad y el MATP, por lo que muchas veces él mismo hacía los guiados en el museo de Barranco.

De esta forma llegamos al nuevo siglo y, desde su primer lustro, Luis Repetto continuó con mejoras en la museografía y espacios de almacenaje del museo. En 2003 consideró importante realizar exhibiciones temporales (tres o cuatro veces al año) para darle movimiento y vida a la institución, así como para mostrar a los visitantes las diferentes líneas artesanales y manifestaciones culturales de las diversas regiones de nuestro variado y rico país.

A la par de su labor en el museo, Lucho, junto con otros compañeros del mundo museístico, en la década de los ochenta formó el Comité Peruano del Consejo Internacional de Museos ICOM-Perú, que forma parte del ICOM Internacional, organismo de la Unesco que se encarga de velar por el desarrollo profesional y técnico de los museos a nivel mundial. Fue presidente del capítulo peruano en varias ocasiones.

Su labor no se limitó al mundo de los museos, pues comprendió que existían otros espacios culturales que necesitaban una intervención para su preservación y difusión; es así que se acercó al mundo de los cementerios patrimoniales y el patrimonio industrial de nuestro país. Participó de forma activa en la formación y desarrollo de la Red Iberoamericana de Valoración de Cementerios Patrimoniales y del Comité Peruano de Patrimonio Industrial. Con ambas instituciones organizó encuentros en nuestro país, así como a nivel internacional. 
En 1999, cuando era director del INC, lanzó la campaña "Adopta una escultura”, por la cual buscó la colaboración de personas y empresas para la restauración de los monumentos que existían dentro del Museo Cementerio Presbítero Maestro; este fue el primer acercamiento a dicho espacio patrimonial, pues poco a poco fue involucrándose y comenzó a investigar y a colaborar con la Beneficencia de Lima para realizar campañas de concientización y visitas guiadas al cementerio. Su labor no se detuvo hasta lograr la edificación dentro del cementerio del Museo de Sitio Presbítero Maestro, durante la primera década del siglo XXI.

Entre otras de sus actividades en el mundo cultural, Lucho incursionó en la radio y la televisión con programas de difusión cultural, destacando el esfuerzo que inició en 2010 en el canal 7 IRTP, con el programa "Museos Puertas Abiertas", con el cual visitó cientos de museos del Perú, difundiendo sus acervos y actividades para todo el mundo. En su afán de ir más allá, realizó algunos programas de museos mexicanos, para mostrarnos nuestras semejanzas y diferencias, de modo que podamos tomar lo mejor de otras experiencias museológicas.

En 2014 recibió la distinción como Persona Meritoria de la Cultura Peruana por parte del Ministerio de Cultura, debido a su destacada labor realizada a lo largo de más de cuatro décadas apoyando la cultura nacional.

El 26 de agosto de 2020, en reconocimiento a su incansable labor, por acuerdo del Consejo Universitario la PUCP, se decidió colocar su nombre en el MATP, por lo cual desde ahora es llamado Museo de Artes y Tradiciones Populares "Luis Repetto Málaga" del Instituto RivaAguiero de la Pontificia Universidad Católica del Perú.

Solo resta mencionar que Luis Repetto Málaga fue un incansable gestor cultural, que supo ver el valor del patrimonio cultural y sus manifestaciones materiales e inmateriales, como uno de los componentes más importantes de nuestra identidad nacional. Su presencia fue ese motor que impulsó tanto la salvaguarda de nuestro patrimonio como la gestión museológica en el país. Por toda esta incansable labor y pasión por su trabajo, no tenemos las palabras adecuadas para expresar la gran falta que nos hace. Continuaremos su legado y memoria a través del trabajo que seguiremos realizando en el museo. Descansa en paz, querido Lucho. 